work in perspective.

The skeleton belonged to an 11-15year-old boy about $160 \mathrm{~cm}$ tall and weighing some $40 \mathrm{~kg}$. (Its predicted adult height and weight would have been $185 \mathrm{~cm}$ and $68 \mathrm{~kg}$.) The body proportions, with long limbs and narrow pelvis, resemble those of modern humans living in tropical climates. Not long ago the immaturity of the specimen would have been regarded as a disadvantage, but the crowns and roots of the teeth, for example, have now proved to be fertile sources of information about comparative development.

In particular, B. Holly Smith's comparative analysis of the physiological age of the skeleton is exemplary, demonstrating a lack of the distinctive human pattern of growth suppression in late childhood followed by a compensatory growth spurt in adolescence. Another characteristic of modern humans is that the brain continues to grow at the fast fetal rate during the first year after birth. In this respect WT15K is like modern humans. It is puzzling, however, that the relationship between brain and body size in WT15K is little advanced over that of the australopithecines who preceded and continued to live alongside it.

A short review can do scant justice to the range, quality and importance of many of the studies included in the volume. Particularly noteworthy are the contributions on the rib cage, which is predominantly like that of modern humans, and the canal for the spinal cord, which is also similar except for a relative narrowing in the thoracic region; these areas have received little attention from hominid palaeontologists. It is a pity that there are no studies of diet or locomotion, but no doubt these are in progress.

Taxonomic analysis reveals that WT15K belongs to the species many refer to as early African Homo erectus and some as $H$. ergaster. The species dates back to 1.8 million years ago, perhaps even earlier. It is a creature that has reached an adaptive plateau substantially more like ours than that of the australopithecines. More importantly and intriguingly, this plateau differs from that of two other species groups presently included in the genus Homo as $H$. habilis and $H$. rudolfensis. We may have cast the net too wide for the genus Homo.

This volume shows how to put the biology into palaeobiology. Despite the poor quality of the photographs, it sets an admirably high standard that will be hard to match. The next challenge is to understand the factors that constrained brain size until much later in hominid evolution.

Bernard Wood is in the Department of Human Anatomy and Cell Biology. The University of Liverpool, PO Box 147, Liverpool L69 3BX, UK.

\section{Creatures deep and small}

John D. Gage

Meiobenthology: The Microscopic Fauna in Aquatic Sediments. By Olav Giere. Springer: 1993. Pp. 328. DM128, SFr128, £50.50, \$89.

THE study of the bottom-dwelling, or benthic, organisms inhabiting aquatic sediments has progressively focused on ever-smaller classes. This reflects the increasing need to understand the role of soft sediments in organic remineralization and pollution in both marine and freshwater environment, where the activity of microorganisms is paramount. The habitat is dominated by the deep-sea bed where much of the metazoan fauna has become miniaturized. Also, the 40 per cent of all fresh water on Earth thought to be stored in deep groundwater systems provides a habitat for microscopic metazoans distributed among deep caves, surface waters and even shallow marine sediments.

Some of these organisms turn out to belong to new phyla such as the Kinorhyncha, or the very recently described Loricifera. Others have been assigned to major new and supposedly primitive taxa, such as the Archiannelida and the new crustacean subclass Cephalocarida, discovered by Howard Sanders in the 1950s. The recognition of an important subcommunity of benthic organisms that can be seen only with a microscope came with pioneering work by Adolf Remane in Germany and later by Delamare Deboutteville in France on what became known as the 'interstitial' fauna of sediments. The terms micro-, meio- and macrobenthos were coined by Mare in 1942 to describe the main size classes in the marine benthic community. But it was not until the past decade that Peter Schwinghamer showed that these empirical divisions correspond to marked abundance peaks in biomass size spectra of benthic animals from a wide variety of aquatic sediments.

These peaks may be determined by physical constraints of the sediment habitat. One peak corresponds to the size range normally considered as 'meiofauna' (about 125-250 $\mu \mathrm{m}$; interstitial lifestyle). Other peaks correspond to the microfauna (generally microflora attached to sediment particles, about $1 \mu \mathrm{m}$ ) and macrofauna (usually less than $250 \mu \mathrm{m}$; occupy the sediment).

Giere's scholarly yet readable monograph on the meiobenthos will be welcomed by all aquatic benthic ecologists. It signals a maturity in the development of this still rather obscure branch of marine biology that will undoubtedly gain wider interest, despite huge taxonomic problems. Its thorough and well-balanced treatment, and useful suggestions for further reading as well as text citations, will also make the study of these fascinating animals more accessible, especially to young aquatic scientists (and particularly to those in the many areas of the world where there is no information at all on the meiobenthos). The well-drawn illustrations and informative summaries of the phylogenetically varied but usually rather conservative body form demonstrate the powerful constraints imposed on life between sediment particles. Indeed, the sediment itself has been taken as of most importance in determining the meiobenthic habitat. More recently, studies using microelectrodes have revealed often sharply discontinuous boundaries in other conditions: for example, high oxygen concentrations are usually associated with biogenic microstructures such as irrigatory burrows of macrofauna. Furthermore, the discovery of meiobenthic metazoans (mainly nematodes) and ciliate protozoan microbenthos that require reducing conditions rich in hydrogen sulphide but apparently completely lacking in oxygen has generated controversy and raised many questions - some see this fauna as a relict from ancient anoxic environments. Although the biogeochemical implications of this sulphide fauna may have been underestimated, it would be unsafe to claim, as did a recent estimate, that 50 per cent of benthic energy flux may be caused by sulphate reduction in shallow marine sediment.

It has been difficult enough to uncover the overall energetic role of meiofauna, and much uncertainty remains. On the one hand, close interaction with microorganisms and detritus has suggested a welldefined and largely closed 'detrital trophic complex'. Giere has examined this assumption, however, and argues instead for strong mutual links between the meioand macrofauna long evident from the large part of the meiofauna comprised of larval stages of macrobenthos.

What is clear is the pressing need for benthic ecologists to examine the benthic ecosystem in a more comprehensive and integrated fashion.

John D. Gage is in the Dunstaffnage Marine Laboratory, PO Box 3, Oban, Argyll PA34 $4 A D, U K$.

\section{Spring Books}

Next week's issue (24 March) contains Nature's Spring Books supplement, featuring, among others, Richard L. Gregory on Francis Crick's The Astonishing Hypothesis; Christopher Longuet-Higgins on Steven Pinker's The Language Instinct; McGeorge Bundy on James B. Conant; and Thomas Banchoff on the philosophy of holes. 